\title{
LAS FRONTERAS DEL HIBRIDISMO: LA NARRATIVA POETICA DE CARICE LISPECTOR ${ }^{1}$
}

\section{BORDERS HIBRIDITY: LYRICAL NOVEL BY CLARICE LISPECTOR}

\author{
Fani Miranda Tabak ${ }^{2}$
}

Resumen: Los estudios acerca de las narrativas poéticas, con sus estructuras propias, consolidan la base de esta investigación en la propuesta de discutir algunos problemas pertinentes a las teorías del género literario. En la relectura de la obra de Clarice Lispector, escritora brasileña del siglo XX, podemos encontrar una nueva forma para la existencia de la poesía: la narrativa poética. Atreves de las estructuras narrativas, la poesía contamina el texto de forma a que manifieste una grande gama de misterio y de paradójica, asimilando el individuo en la busca de sí mismo, vertiendo distintas cuestiones acerca de la condición humana de existencia. Observamos, aún la tensión expresa por la poesía en su forma narrativa como una poderosa arma para explorar la temática de la búsqueda ontológica.

Palabras clave: narrativa poética; Clarice Lispector; búsqueda ontológica.

Abstract: Studies of the lyrical novels, with its own structures, strengthen the basis of this research proposal to discuss some issues relevant to theories of literary genre. In rereading the work of Clarice Lispector, Brazilian writer of the twentieth century, we can find a new way for the existence of poetry: lyrical novel. Dare narrative structures, poetry polluter text form to manifest a large range of mystery and paradox, taking in the individual in search of himself, pouring various issues about the human condition of existence. We note, even the tension expressed in poetry in narrative form as a powerful weapon to explore the theme of ontological search.

Keywords: lyrical novel; Clarice Lispector; ontological search.

El concepto de romance lírico o narrativa poética, como traducimos del francés ${ }^{3}$, se presenta, inicialmente, como algo paradójico. Partiendo de ese punto de vista, tenemos de encarar el hecho de que la narrativa se deba desarrollar

\footnotetext{
1 Artigo publicado em sua primeira versão em: Miranda Tabak, Fani. Las fronteras del hibridismo: la narrativa poética de Clarice Lispector . Lit. lingüíst., 2006, no.17, p.49-63. ISSN 0716-5811

${ }^{2}$ Professora da Universidade Federal do Triângulo Mineiro.

${ }^{3}$ Récit poétique.
} 
como un género de ficción garantizando que personajes, acciones e ideas, hasta mismo las opciones morales, nos sean presentadas de una forma dramática. Por otro lado, la expresión lírica de alguien que habla, piensa o reflexiona interiormente, en determinadas narrativas, se torna tan relevante que acaba por ofuscar las acciones directas y crea una trascendencia repetida de los hechos reproducidos. Esa dicotomía, sobre la cual está depositada la narrativa, tiene su centro fijado en la fusión que ocurre entre el concepto de acontecimiento y una alusión continua a la textura del imaginario. Ese problema está bastante explorado por Jean Burgos y nos remite a una aproximación entre la trayectoria de la imagen yendo al encuentro del imaginario:

L'image, pour sa part, ne reste image qu'autant qu'elle est considérée dans son rôle vivant qui la situe au commencement et la porte au-delà de ce qu'elle énonce. Estce à dire que la seule rencontre de forces venues de deux mondes complémentaires suffira à lui donner, outre sa force originelle, une direction propre, à l'acheminer vers un sens? II ne le semble pas, et cela pour deux raisons majeures, qui finissent par se confondre: la première, c'est que le dynamisme de l'image est lié en toute priorité à la fonction symbolique de cette image; la seconde, que l'image poétique, même envisagée dans cette dernière fonction et donc point refermée sur elle-même, ne peut prendre signification qu'à partir du moment où elle est située dans son tissu de l'imaginaire.(Burgos,1982,p.79-80)

La eclosión de las imágenes construye la base organizadora de una perspectiva aparente del mundo en las narrativas poéticas, como una especie de reflejo del real. Comprendida dentro de una perspectiva individual, construida por el imaginario, ejerce la función de protagonizar el sentido simbólico de la búsqueda interior, pues es justamente en ese espacio que las grandes transformaciones de la vida se refleten. El espacio, por eso, se sitúa siempre como un lugar privilegiado, representando un escenario específico y misterioso. Las referencias al mundo exterior, en esas narrativas, asumen un color del estado de 
ánimo en que el yo se ve inmerso. El paisaje o la naturaleza no son solamente vistos y descritos como aparentemente son, mas especialmente sentidos por la intensidad de un foco narrativo personal y subjetivo. Esa característica es marcada por una necesidad de absorber el espacio atreves de los sentidos, es decir, el ser de la narrativa poética se multiplica para tentar aprehender el mundo de distintas maneras. Además de que el espacio detiene esa verdad oscura, él es casi un personaje pues prolonga la subjetividad de quien percibe e imagina.

De esa manera, la narrativa poética acaba produciendo un efecto desconcertante en el lector, pues le presenta las acciones como un elemento fundamental para el desarrollo del romance, pero continuamente lo transporta por un segundo camino, un segundo texto, con sentidos totalmente fragmentados por la visión lírica del yo. En ese desvío de la mirada, que contempla la imaginación más profunda del ser, concentrase la propia desestructuración de la noción de género y la metáfora poética de lo que aparentemente parece completo. Ese tipo de género híbrido destaca la importancia de la revisión de los conceptos tradicionales de género literario y demuestra la continua y frágil separación entre la prosa y la poesía, especialmente en los últimos dos siglos. El concepto de romance lírico o de narrativa poética pone en discusión la idea de distinción genérica y resalta la hibridación de la literatura moderna. El crítico francés JeanYves Tadié, analizando las estructuras de narrativas poéticas, indica como uno de los grandes recursos de esas narrativas el uso recurrente de metáforas. Como es un uso abusivo, en esas narrativas, revela el surgimiento de otro texto, paralelo al primero, que alcanza al lector de forma que este se presente enredado por esa tela de araña. Siguiendo esa perspectiva, las acciones directas, la historia, los personajes, pasan a un según plan para que emerja la explosión de contrastes de la percepción lírica de un individuo. La eclosión de esa verdad crea la posibilidad de un punto de vista interior, hace una inmersión en la reflexión del alma humana, especialmente en la búsqueda ontológica. De esa forma, el foco narrativo crea nuevas perspectivas, pues representa una realidad que es transgredida por la representación constante de la conciencia interna del yo y reflexionando también 
en el tú. Es como una especie de universalización del yo, más profundamente consciente del estar viviendo en el mundo de hoy.

Como bien resalta Tadié, el concepto que establece de récit poétique está totalmente atrapado a la posible estructura y relación de los elementos narrativos y poéticos:

Le récit poétique en prose est la forme du récit qui emprunte au poème ses moyens d'action et ses effets, si bien que son analyse doit tenir compte à la fois des techniques de description du roman et de celles du poème: le récit poétique est un phénomène de transition entre le roman et le poème. La tâche du critique est alors de proposer un modèle, ou une théorie, que l'étude des textes devra vérifier ou infirmer. L'hypothèse de départ sera que le récit poétique conserve la fiction d'un roman: des personnages, auxquels il arrive une histoire en un ou plusieurs lieux. Mas, en même temps, des procedés de narration renvoient au poème: il y a là un conflit constant entre la fonction référentielle, avec ses tâches d'évocation et de représentation, et la fonction poétique, qui attire l'attention sur la forme même du message. (Tadié, 2000, p.7-8)

En esa dirección aproxima también ese tipo de construcción poéticonarrativa a la composición de una obra musical, pues acaba estructurando una constancia de repeticiones e tensiones entre sus elementos, de la misma manera que vemos en la música. La acción lírica se torna, de esa forma, una acción esencial que liga y tensiona elementos más estáticos (de un mundo preestablecido) y elementos construidos por una imaginación que dialoga consigo misma en un ejercicio no solo poético como por veces metafísico.

Si unimos los conceptos de Tadié y del crítico norte-americano Ralph Freedman, responsable por la expresión lyrical novel, tendremos percibido un escenario donde la textura imaginaria del ser, los caracteres narrativos y poéticos representan un desdoblamiento del yo como una supra realidad, es decir, la estructuración de una conciencia reveladora discursiva. 
Ese desdoblamiento, como afirma Freedman, aproxima narrativa y poema lírico, pues su estructura busca objetivar no solo hombres y épocas, como también una experiencia y un tema en que hombres y sus vidas, lugares e eventos, fueron usados. Aquí, como tratamos de Clarice Lispector, más adelante, no podemos dejar de mencionar la relación muy fuerte con los temas de mujeres y sus vidas, lugares, eventos, y etc.

Ese constante conflicto interno de la narrativa termina construyendo el efecto poético, que no debe ser visto solamente como una grande estructura metafórica, sino también como el resultado de una combinación innovadora entre recursos poéticos que buscan la representación de una voz individual en construcción y de la propia representación del lenguaje como encantamiento.

Partiendo, en un primer momento, de la presencia del mito en la narrativa poética, y revolviendo algunas de las ideas presentadas por Tadié, nos vemos ante el rescate usual de esa estructura como una forma simbólica para captar el mundo. El mito, por lo tanto, acaba constituyéndose en un icono para la base de la transposición de un pensamiento lírico, que se recusa a perecer. No parece extraño que las narrativas poéticas, muchas veces, utilicen ese recurso como base para la estructura de una trascendencia.

Esa trascendencia persigue, con esa peculiaridad, la creación de un nuevo espacio narrativo, donde están concentradas situaciones reales, pero delante de la circularidad lírica de un poeta. Ese transporte constante, que Tadié reconoce como parte integrante en la narrativa poética, conduce necesariamente a un nuevo efecto, inclusive porque el sistema de símbolos puede ser leído como una grande metáfora. La redundancia en lo que dice respecto a la trascendencia establece una relación directa con la desconstrucción del mundo moderno. De esa forma, establece una capacidad de transformar o actualizar el tradicional, trayendo para el universo narrativo atemporalidad y universalismo lírico que hasta este momento parecían privilegios de la poesía.

Como consecuencia, una de las cuestiones esenciales ligadas al estudio de la narrativa poética centrase en la discusión del foco narrativo. En ese tipo de 
composición, donde el desdoblamiento de una conciencia es fundamental para la acción romanesca, se ve comprometida la noción tradicional de un foco narrativo único, constante. Esa nueva perspectiva acaba introduciendo la percepción de un foco variable, subjetivo e ambiguo, lo que nos remite, otra vez, al problema de la paradoja, una vez que esa subjetividad parece más inherente al ser de la poesía que al del romance.

La proximidad destacada universaliza, también, el locutor y el interlocutor, como si todos fuesen convocados para hacer parte de la narrativa, como en una estructura circular. La narrativa, dirigida por un foco instable e oscilante, no puede avanzar progresivamente, sino profundarse en la representación de una conciencia en plena angustia de ser. El efecto único, de que Poe hablara, se transforma, por lo tanto, en un efecto catastrófico, caótico, doloroso y constantemente repulsivo. La narrativa poética no cuenta una historia, ella personifica dentro del lector las inquietudes de un alma, y revela la esencia humana lírica más profunda del ser que busca a sí mismo.

Dentro de esos parámetros nos surge el desarrollo de una escucha minuciosa de su representación dentro de la prosa moderna y contemporánea escrita por mujeres en Brasil. Para establecernos una configuración más precisa de esa forma de representar la búsqueda ontológica dialogamos con la obra de Clarice Lispector, autora que se ha canonizado atreves de sus narrativas poéticas.

En uno de los grandes escritos críticos sobre el proyecto de escrita de Lispector, más específicamente del juego de la identidad, Benedito Nunes hace una observación reveladora acerca de la singularidad presente en la autora:

Esse romance de estréia trouxe para a literatura brasileira de ficção, como foco da arte de narrar, com as implicações estéticas e formais conseqüentes - do monólogo interior à quebra da ordem causal exterior, das oscilações do tempo como duração (durée) ao esgarçamento da ação romanesca e do enredo - a perspectiva da introspecção, comum à novelística moderna. Mas em vez de constituir um foco fixo, detido na exploração dos momentos de vida, desses "little 
separate incidents that one lived one by one", aos quais se reportou Virginia Woolf em To the Lighthouse, o ponto de vista introspectivo, dominante inclusive nos contos de nossa escritora, ofereceria o conduto para a problematização das formas narrativas tradicionais em geral e da posição do próprio narrador, em suas relações com a linguagem e a realidade, por meio de um jogo de identidade da ficcionista consigo mesma e com seus personagens - jogo aguçado até o paroxismo em $A$ paixão segundo G.H., que contém uma das chaves do desencadeamento desse processo. (Nunes, 1995, p.160-161)

Destacando, desde el inicio, una forma narrativa problematizada, Nunes deja claro que la autora esta en constante juego con sus personajes e con sí misma atreves de la lenguaje. Para explorar un poco esa temática, nos volveremos específicamente para el libro Uma aprendizagem ou o livro dos prazeres, publicado por la autora en 1969, puesto que sea una obra que gano poca celebración critica en general para la fortuna de la autora.

La narrativa en cuestión hace brotar, desde el inicio, la problemática del desdoblamiento del yo, sea en un falso monólogo interior, como en una inmersión en la crisis de identidad, temática elegida tantas veces por Lispector. Las técnicas utilizadas por la autora comprometen el concepto tradicional de narrativa y presentan una forma de narrar que dialoga directamente con la noción de lo paradójico. Ese diálogo se vuelve una transfiguración del discurso que acompaña la mente humana, como si la narrativa revolviese un estado de conciencia íntima avasalladora y contrastiva del instante. Ese contraste es nítidamente percibido por las idas y venidas del mirar que va captando en las imágenes del mundo una aparente totalidad sensible que promueve la universalidad.

De esta forma, tenemos la presencia de un sentimiento perturbador, pulsante, que engendra el acto de narrar, el acto del pensar y el acto del sentir. Esa relación no está bien nítida en sus discursos, pues ella requiere la reflexión de procesos poéticos que, inicialmente, no les son característicos. La apropiación de 
elementos poéticos por su discurso narrativo mantiene una tensión vibrante entre los límites de lo que convencionalmente llamaríamos de género narrativo. Las imágenes, que reflejan esa búsqueda esencial por la palabra poética, se tornan diferentemente significativas. Constituyen el punto de partida para una desecación absoluta dese espíritu que está agonizando en su interioridad. En esa perspectiva, la narrativa lírica o poética intercala la acción y reacción con el reflejo de una conciencia lírica en plena formación, y consecuentemente producto de un discurso que todavía está en estructuración.

\section{Uma aprendizagem ou o livro dos prazeres.}

La obra de Lispector que aquí analizamos presenta, de forma desordenada, un breve momento en la vida de su protagonista. Lori, una conciencia solitaria todavía sin identidad, busca en el amor dedicado a un filósofo el diálogo profundo consigo misma. La protagonista es mediada por otras voces, que reflejan, como en un juego de espejos, la condición angustiante para la transcendencia soñada desde el principio. En esas mediaciones, que constituyen monólogos interiores y diálogos reflectados, se instala el universo poético, no como forma absoluta del devaneo, sino como estructura circular de la búsqueda por el entendimiento de sí misma. Cuando analiza las distintas formas en el romance de Lispector, Benedito Nunes indica el surgimiento de un sistema dialógico a lo largo de su obra:

O que há de realmente novo em Uma aprendizagem ou o livro dos prazeres, contrastando com os romances anteriores, é que a narrativa está polarizada pelo diálogo e não pelo monólogo. Embora presa do mesmo dilaceramento que afeta Joana e Virgínia, Lori, a personagem de Uma aprendizagem, que conhece a extrema solidão desagregadora de G.H., encontra em Ulisses, um professor de filosofia, o interlocutor que a devolve à si mesma e à realidade. Ao contrário de um conflito intersubjetivo da protagonista com o personagem principal mediador, vamos assistir a uma diferente espécie de relacionamento, como já 
nos mostra o pacto firmado entre eles: Ulisses só possuirá Lori, que já teve cinco amantes eventuais, quando esta puder a ele entregar-se de corpo e alma, numa união amorosa completa e sem reserva. A ação desse romance, que ainda corresponde a uma busca, podendo ser enfeixada na trajetória que a protagonista percorre da solidão à comunhão, do auto isolamento ao abandono na pessoa do outro que a identificará consigo mesma, põe face a face, em vez de uma protagonista e de um mediador externo, duas consciências que se reconhecem, a princípio de maneira reticente, para se comunicarem em seguida através do silêncio e da palavra, da carne e do verbo. (Nunes,1995, p.78-79)

Aunque Nunes destaque la diferencia en ese romance de la perspectiva monologal, deja claro que todas las cuestiones pertinentes a la temática de la búsqueda ontológica están allí. Lori, en realidad, emprende un viaje, no a un luego común, pero sin rumbo a la tentativa de reconocimiento de su propia identidad. Esa búsqueda, marcada por la crisis interna sugerida desde las primeras líneas de la narrativa poética, se vuelve en una búsqueda polifónica, pues establece un foco narrativo de sueño, de angustias y pesares en contraposición a la ordinariez del mundo natural. Con esa perspectiva, el personaje no promueve una acción directa que llevará al desenlace, sino contrariamente, mantiene un drama que conduce al espesamiento final y a su construcción de héroe dentro de la propia narrativa. En ese confronto del yo y con el mundo actual nos aparece la idea del héroe nuevo, que como bien menciona Joseph Campbell nos conduce al problema de toda la humanidad en la modernidad:

O problema da humanidade hoje, portanto, é precisamente o oposto daquele que tiveram os homens do período comparativamente estáveis das grandes mitologias coordenantes, hoje conhecidas como inverdades. Naqueles períodos, todo o sentido residia no grupo, nas grandes formas anônimas, e não havia nenhum sentido no indivíduo com a capacidade de se expressar; hoje, não há nenhum sentido no grupo - nenhum sentido no mundo: tudo está no 
indivíduo. Mas, hoje, o sentido é totalmente inconsciente. Não se sabe o alvo para o qual se caminha. Não se sabe o que move as pessoas. Todas as linhas de comunicação entre as zonas consciente e inconsciente da psique humana foram cortadas e fomos divididos em dois. (Campbell,1997, p.372-373.)

Si nos vemos divididos por dos, por lo menos, la concepción del héroe encuentra una nueva razón de ser, aunque ella se vea como una forma sin salida en el sentido de que está construida para aplacar la angustia de buscar. Los mediadores se tornan máscaras, caminos personificados por la misma voz pérdida en búsqueda de su expresión. Esa transgresión de los límites convencionales de la narrativa pura transforma el espacio y el tiempo narrativos en espacio y tempo líricos. Para Ralph Freedman, al comentar las técnicas de escritura de Virginia Woolf, el tiempo y el espacio de la narrativa poética destruyen la linealidad, re arreglan el mundo a su manera: Worlds in time and space are not precisely reproduced but rearranged in aesthetic designs which become universal and symbolic.(Freedman, 1971, p.188)

De esa forma, la narrativa busca una estructura complementar antagónica, sobre la cual observamos las dicotomías entre el acto de ser, de escribir y el acto de reproducir el mundo. El choque de ideas, pensamientos y acciones promueven un intervalo literario, convocando para dentro de la obra el poder inagotable de la palabra poética. Esa convocación traduce una necesidad que está más allá del simple acto de narrar, que se destaca principalmente como un acto de búsqueda, de comprensión, de aprendizaje, estructurando una transformación no terminada, que nos lleva a reflexionar directamente sobre los problemas que envuelven la meta ficción.

Como ya mencionamos, el viaje de Lori, una conciencia todavía en formación, se estructura en el reflejo inicial de la falta de personalidad, marcada por la cesión del nombre. La búsqueda angustiada por una esencia propia, capaz 
de restablecer la unidad, refleja evasión lírica que transforma el poder de la palabra en potencia del humano. La palabra deja de representar el sentido ordinario del mundo para transformarse en una construcción continua de la personalidad, un diálogo con el instante iluminador.

Así, las repeticiones seguidas de palabras o expresiones, en Uma aprendizagem ou o livro dos prazeres, tornan-se ecos de una poética singular capaz de reproducir aquello que parece no ser reproducible: el pensamiento. Esas marcas, comunes a la poesía, desestructuran el desarrollo de una narrativa lineal, pues reconducen el sentido del texto para otros planos simultáneos. Esos planos revelan metafóricamente la construcción de identidad y consecuentemente se abren como refugios de una voz lírica inacabada:

(...) sentou-se para descansar e em breve fazia de conta que ela era uma mulher azul porque o crepúsculo mais tarde talvez fosse azul, faz de conta que fiava com fios de ouro as sensações, faz de conta que a infância era hoje e prateada de brinquedos, faz de conta que uma veia não se abrira e faz de conta que dela não estava em silêncio alvíssimo escorrendo sangue escarlate (...) (Lispector, 1998, p.14)

El refugio, que se refleja en el yo y en el otro, produce el encanto y el vuelo de la mente. Lori, mujer sensual y simbólica, se desvía innúmeras veces de su encuentro carnal, para encarar la dolorosa travesía de sí misma y el propio silencio. Uma aprendizagem ou o livro dos prazeres hace emerger la cuestión del ser, no como forma acabada, más en una dialéctica constante. Esa sirena, que encanta los hombres, se convierte en una personificación de la revelación de su propio canto, con su propia sensualidad. Ese encuentro, que revela su poder mítico, la establece como sujeto de una iniciación. Eso dialoga con lo que Tadié evidencia en las narrativas poéticas como una constante mítica: Or le récit poétique, qui n'est pas un roman, retourne à un état proche du récit mythique: l'intrigue passionnelle y compte peu, l'individu, souvent anonyme, accomplit les gestes qui font de lui le sujet d'une initiation (Tadié, 2000, p.11). 
La revelación del yo, desproveída de sentido, estructurase como una construcción cíclica e discontinuada. El anonimato del personaje, que pregunta desde el primer momento -¿Quién soy yo? - , expresado por tremolares y sensaciones, construyen el espacio para el rito iniciativo. Así, Lori, una profesora primaria que vive en Rio de Janeiro, despierta dentro de su vida cotidiana en un terremoto existencial que revisita el fuego adormecido de los dioses. Inmersa en la doble llama de la vida, amor y erotismo, encuentra un espacio poético que reúne su cuerpo y su alma. Para encontrar a si misma debe dedicarse a la longa y angustiante aventura del aprendizaje a través del placer. El amor, se fundamenta aquí, como un mito del descubrimiento de la potencia del ser. En esa ansia de descubrir su imagen van incorporándose símbolos, que representan la "proteización" de las formas corpóreas como transmutaciones de la búsqueda por si misma:

(...) -usaria brincos? Hesitou, pois queria orelhas apenas delicadas e simples, alguma coisa modestamente nua, hesitou mais: riqueza ainda maior seria a de esconder com os cabelos as orelhas de corça e torná-las secretas, mas não resistiu: descobriu-as, esticando os cabelos para trás das orelhas incongruentes e pálidas: rainha egípcia ? não, toda ornada como as mulheres bíblicas, e havia também algo em seus olhos pintados que dizia com melancolia : decifra-me, meu amor, ou serei obrigada a devorar, e (...) (Lispector, 1998, p.17)

(...) de repente a máscara de guerra da vida crestava-se toda como lama seca, e os pedaços irregulares caíam no chão com um ruído oco. E eis rosto agora nu, maduro, sensível quando já não era mais para ser. $\mathrm{E}$ o rosto de máscara crestada chorava em silêncio para não morrer.(Lispector, 1998,p.86) 
El caballo negro y lustroso, salvaje y dulce, relinchando dentro de su cuerpo, gana las dimensiones míticas de origen. Galopa por tiempos inmemorables, transciende el espacio-materia e instaura la pulsación salvaje de la existencia de la vida. Los fenómenos de la naturaleza se vuelven símbolos de una búsqueda interna por paz abrigadora. Recorriendo los caminos de las estaciones, la narrativa poética construye la imagen del ser naturalmente fundida al espacio. Lori y Loreley, una dicotomía que brota en la narrativa, desnudan el confronto entre el personaje marginal y sencillo de una vida moderna y el antiguo mito:

Loreley é o nome de um personagem lendário do folclore alemão, cantado num belíssimo poema por Heine. A lenda diz que Loreley seduzia os pescadores com seus cânticos e eles terminavam morrendo no fundo do mar, já não me lembro mais de detalhes. Não, não me olhe com esses olhos culpados. Em primeiro lugar, quem seduz você sou eu. Sei, sei que você se enfeita para mim, mas isso já é porque eu seduzo você. E não sou um pescador, sou um homem que um dia você vai perceber que ele sabe menos do que parece, apesar de ter vivido muito e estudado muito. (Lispector, 1998, p.97)

En esa perspectiva, la narrativa poética de Lispector crea un nuevo mundo para el personaje, con su espacio y tiempo, que nos son sugeridos con la delicadeza de un poema lírico. El espacio de la casa de Lori es representado, durante la narrativa, como un refugio, un escondite. Funciona como un abrigo, que la protege de sí misma y le causa una demora funcional del auto conocimiento, contribuyendo para la demora del saber y del encuentro con su yo. En la casa, el tiempo y los espacios son rememorados pero no avanzan, es necesario que ella salga de ese espacio para que la epifanía ocurra. El encuentro final con la dura carne del hombre amado transciende para la representación de su encuentro con la personalidad, con el entendimiento, con la palabra poética. El amor, consiguientemente, es el vehículo para la reflexión de una intimidad avasalladora, 
que destruye por dentro. Los dos puntos, que encierran la narrativa, construyen una epifanía del auto-conocimiento, de la libertad individual de ser y de elegir.

La trayectoria ritualista, que se desarrolla a lo largo de la narrativa, confirma la existencia de un mundo paralelo e imaginario controlado por un sistema de símbolos. El proceso lineal de construcción del personaje es substituido por el profundar de las zonas del inconsciente que detienen la ausencia de identidad. Lori, que parece morir dentro de su alma inacabada, renace dentro de la imagen femenina mítica para reencontrar su verdadera persona. Recorriendo los caminos tortuosos de la angustia y de la duda, de la incomprensión del divino, del orgullo herido, tiene que someterse a sí misma para poder empezar a sentir, experimentar, aprender y finalmente encontrar algo que refleje su existencia. E aprendizaje es mítico, pues el revela la única verdad que el individuo nunca ha dejado de buscar; la protagonista reconoce eso desde el inicio de sus pensamientos $-A$ mais preemente necessidade de um ser humano era tornar-se humano. (Lispector, 1998, p.32)

La búsqueda ontológica es rellenada por el mito, que comporta en su estructura el conocimiento, la sabiduría milenaria, compartiéndola con los sentidos de la vida psíquica y afectiva. A través del mito podemos reunir en una suspensión de tiempo el presente, el pasado y el futuro, y abrazamos su deseo de universalizar algunas verdades de la condición humana de existencia. Esa perspectiva, parecenos que se aproxima, ilusoriamente, de lo que Horacio ha denominado en su oda, Exegi Monumentum, pero de forma a que esa perennidad sea capaz de ser elegida para el individuo.

En ese sentido, la presencia de Lori, como protagonista, en realidad exprime una confluencia de imágenes femeninas. En ese encuentro surge el espacio de persecución de la lucha interior y la reflexión acerca de la condición humana y frágil.

Dialécticamente entre el representar y el ser se instaura un universo fragmentario y des construido internamente por una conciencia humana que se presenta inconsciente. Esa fragmentación se realiza de forma lírica, circular y 
paradójica, para que el acto de narrar se transforme en potencia viva del lenguaje, en un acto complejo y representativo de una totalidad soñada.

La protagonista, mediada por un hombre de la filosofía, parte en la búsqueda del inesperado, del proyecto personal de escritura y de sueño. Lori, envuelta por un filósofo que solamente le aceptará en el momento que ella se encuentre, queda deparada con la dura realidad de la falta de imagen, la falta de carne y del verbo.

De esa manera, la filosofía que parece tener respuestas directas para la angustia humana, se vuelve a indagar sobre un viejo enigma: ¿Quiénes somos? ¿Qué deseamos?

El aprendizaje se estructura como una gran metáfora de la necesidad incesante, un guía de luz para la crisis de identidad. El viaje, que puede durar un día o mil años, desnuda la necesidad continua de trascender el mundo físico, la necesidad de recuperar la imagen poética perenne de lo humano.

Ese sueño, sugiere la liberación de las amarras impuestas por la modernidad, especialmente en los espacios urbanos, con sus convenciones sociales y con la grande angustia de sentirse solo. Clarice Lispector dialoga como una fase opuesta de la misma moneda, transformando la soledad de la mujer moderna en poder inagotable de la poesía, haciéndola cantar para que ordene una narrativa de sí misma. Uma aprendizagem ou o livro dos prazeres alcanza, de esa forma, una estructura mezclada, que tiembla entre las bases de la narrativa y del poema, logrando un nuevo espacio, una nueva forma para existir.

\section{Conclusiones}

La narrativa de Clarice Lispector mimetiza una aventura del pensamiento en dirección al conocimiento humano. Despierta en el lector la idea de las verdaderas batallas, que ocurren en el silencio de la mente. El encuentro con el otro, con el reflejo, con el doble, transforma esta odisea moderna en una alegoría de la propia 
angustia de vivir, idea que es explorada por Lispector desde el inicio de la narrativa cuando la imagen del caballo se acerca:

Existe um ser que mora dentro de mim como se fosse casa dele, e é. Trata-se de um cavalo preto e lustroso que apesar de inteiramente selvagem - pois nunca morou antes em ninguém nem jamais lhe puseram rédeas nem sela- apesar de inteiramente selvagem tem por isso mesmo uma doçura primeira de quem não tem medo : come às vezes na minha mão. Seu focinho é úmido e fresco. Eu beijo seu focinho. Quando eu morrer, o cavalo preto ficará sem casa e vai sofrer muito.(LISPECTOR, 1998, p.28)

La fusión entre Lori y el caballo atrae para el texto una tradición literaria presente desde la lliada, construyéndole una nueva perspectiva mítica. Revertiendo el pasado histórico de las grandes narrativas, el yo concibe una nueva forma de existencia, proyectando sobre el origen mítico una interpretación de sí misma. Como ser humano angustiado, el origen funciona como punto de partida para el sentido incomprensible de su falta de identidad. La transposición simbólica de esa angustia, en diferentes imágenes, posibilita la estructuración de la búsqueda dentro de una interioridad más profunda, con orígenes lejanos.

Tocarse a sí misma, el acto más difícil y doloroso del ser, es la gran aventura de Lori. Los obstáculos, a través de los cuales ella presiente su ser, la enseñan y la aterrorizan. Descubrirse no es simplemente un acto necesario, es heroico, pues el confronto entre el yo y el mundo y la construcción de la subjetividad inherente al ser humano se tornan reflejos de dolor y placer.

La narrativa espeja el desarrollo de una mente creadora capaz de captar las varias facetas de lo real, apartando el mundo y sintiéndose al mismo tiempo extraña en su individualidad sensorial. La construcción del ser, que busca la identidad, es marcada por la presencia de lo insólito, que funciona como una denuncia de las apariencias de lo cotidiano: pues las cosas poseen una existencia bien más rica de la que conseguimos visualizar en el día común. El acto de creación es transformado en posibilidad de percepción de una realidad que se 
pulveriza y el drama humano se cristaliza en el lenguaje, que hace brotar la angustia de vivir en su propia estructura.

La angustia es el reflejo de la necesidad de liberación, la búsqueda ontológica es mediada por la tentativa de descubrir nuevas formas de nacer. Formas esas que solo son alcanzadas por una fuerza propulsora lírica de la escrita. Escribir es una parte de recreación de esa nueva vida, representa un movimiento de aprendizaje y percepción. La fuerza creadora de la palabra transforma el pasado, reordena el presente y sueña el futuro. El pasaje entre el yo y el mundo está centrado en el lenguaje, en la poesía. Eso evidencia la proximidad ente la narración y la conciencia del individuo. Con esa perspectiva, el lirismo de la conciencia amplifica los sentidos de las cosas, de los lugares y de los seres, descubriendo nuevas formas posibles. El tiempo y el espacio revelan la subjetividad que quiere convertirse en realidad, instaurando la verdad del instante profundo que se vierte del alma:

-Meu amor, você não acredita no Deus porque nós erramos ao humanizá-lo. Nós $O$ humanizamos porque não $O$ etendemos, então não deu certo. Tenho certeza de que Ele não é humano. Mas embora não sendo humano, no entanto, Ele às vezes nos diviniza. Você pensa que-

-Eu penso, interrompeu o homem e sua voz estava lenta e abafada porque ele estava sofrendo de vida e de amor, eu penso o seguinte:

(LISPECTOR, 1998, p.155)

Lispector, de esa forma, lanza un nuevo juego de dados al lector. ¿Cómo termina? No termina, dos puntos anteceden un pensamiento que no será pronunciado. El lenguaje se intercala, elíptico, para promover el silencio absoluto de la respiración, porvenir.

La angustia de vivir, ya que existir es experimentar y retornar siempre al inicio, demuestra que la búsqueda ontológica es una necesidad única, puesto que A mais preemente necessidade de um ser humano era tornar-se humano. (Lispector, 1998, p.32) 


\section{Referências:}

AUERBACH, E. Mimesis. São Paulo: Perspectiva, 1994.

BURGOS, J. Pour une Poétique de L’Imaginaire. Paris: Éditions du Seuil, 1982.

CAMPBELL,J. O Herói de mil faces. Trad. de Adail Ubirajara Sobral. São Paulo: Cultrix/Pensamento, 1997.

DUfFREnNE, M. O Poético. Porto Alegre: Editora Globo, 1969.

EIGELDINGER, M. Jean- Jacques Rousseau -Univers Mythique e Cohérence. Neuchatel : A La Baconnière, 1978.

ELIADE, M. Aspects du mythe. Paris: Gallimard, 1969.

FREEDMAN, R. The Lyrical Novel. New Jersey: Princeton University Press, 1971.

HUMPHFREY, R. O fluxo de consciência. São Paulo: Mc. Graw-Hill do Brasil, 1976.

LISPECTOR, C. Uma aprendizagem ou livro dos prazeres. Rio de Janeiro: Rocco, 1998.

TADIÉ, J-Y. Le récit poétique. Paris: Presses Universitaires de France, 2000. 